With regard to so-called physical exercises, postural scoliosis is due, not to muscular weakness, but to deficiency of the habitual subconscious state of reflex activity which noimally maintains the upright attitude. The object of treatment; therefore, is not to strengthen or develop particulat muscles or groups of muscles, but to redevelop a habit-the postural reflex. This may. be done now in the same way as originally in early clildhood-namely, by voluntary muscular effort constantly repeated until it becomes involuntary, subconscious and habitual-in other words, by exercises.

Exercises are only one of the means to this end. They should be dosigned to correct faulty postures as sưch and not with the idea of developing particular muscles. "Inter. mittent exercises are of little use in themselves. The patient must be got to strive for a constant effect. Her co-operation is essential, and to this end the personality of her instructor is of far more importance than the particular exercises dove.

Restoration of the postural reflex is the basis of all curative treatment of 'scoliosis. If a curvature is flexible, so that it can be straightened by active or passive movement, it will be lrept straight when the postural reflex is re-established, and the patient will be cured.

A curvature that is partly fixed by structural changes can be corrected only so far as it can be made flexible. The flexibility of a structural curve can often be materially increased by active and passive corrective movements, but rarely, if ever, can a structural curve be made completely flexible and therefore curable by these means. A moderate amount of fixed residual curvature may be held in check indefinitely, if the postural reflex is re: established. Such a curve, however, tends slowly to increase mechanically under the influence of gravity, just as an occupational or adaptation curvature does, and many such cases eventually show a poor return fôr the time, labour, and money that has been expended on their active treatmont. Therefore, if a curvature is not held in check by a reasonable amount of active treatment, it should be given mechanical support.

With regard to forcible correction and the application of plaster jackets in scoliosis, it is known that, apart from its effect on the distortion of the ribs, this method, like others, depends for its success upon flexibility of the spine. Most orthopaedic surgeons will agree with the finding of the Scoliosis Committee of the American Ortho. paedic Association (1916) that no case of fixed scoliosis has yet been shown to have been corrected in the anatomical sense by any method. At best, forcible correction is but a preliminary measure, and if it is not followed by restoration of the postural reflex or by efficient mechanical support, it is both useless and harmful.

The day has passed when it was customary to hang a so-called spimal support on every crooked back. Nearly everyone now treats scoliosis by exercises, "und I think that exercises are indicated in the hajority of cases. But $I$ would plead for discrimination in their use, as in that of any other therapeutic measure - Some people have made almost a fetish of exercises. One sees cases so treated, literally for years, without any appreciable benefit, and a spinal support is often ordered only as a last resort." Some cases are quite unsuitable for treatment by exercises from the beginning. Exercises in many ca'ses are given without appreciation of their real purpose. They are only one of the means to an end-namely, restoration of the postural reflex, and to attain this end it is the patient, and not merely her spinal column, that requires treatment.

$$
\text { REFERENCEs. }
$$

1 Brain, 1915, vol. xxxviii, p. 191. 2 Jourt. of Physiol., 1897, vol. xxi, p. 1. 8 Aroh. di Fisiologia, 1904, vol. ii, p. 132. A Anat. Anzeioer, 1910, Bd. xxxv, B. 481 . F Folia Neurobiologica, 1914 , Bd. vii. 8. 378 and 837 . Soc., 1908, B, vol. 1xxx, p. 552. 7P̈ftloer's Archiv, 1912, Bd. cxlv, Boy. et seq. Beutsche Aerztezeitung, 1900 .

$$
\text { ( } \text { To be continued.) }
$$

THE Department of Social Hygiene in the League of Red Cross Societies, whose headquarters are at Geneva, will in future be known as the Department for Combating Venereal Diseases. Mr. Walter Clarke has been appointed Chief of this Department and Lieut.-Colonel Ritchie, Assistant Chief. The League has published in English, French, German, Italian, ap Spunish two pamphlets concerning the fight against venereal diseases, eptitled respectively "The venereal disenses survey" and "Venereal diseases -a challenge to the Red Cross."

\section{(Blibro-sharpey Mertures}

oiv

\section{THE NATURE OF FLUTTER AND FIBRILLATION OF THE AURICLE.} BY

THOMAS LEWIS, M.D., F.R.C.P., F.R.S., PHYSICIAN OF THE STAFF OF THE MEDICAT RESEAROH COUNCIL: PHYSICIAN TO UNIVERSITY COLLEGE HOBPITAL, LONDON ; HONORAKY CONSCLTING PHYSICIAN TO THE MINISTRY OF PENSIONS.

LECTURE II.-AÚRICULAR FIBRILLATION.*

In the first of these lectures $I$ have endeavoured to put before you the chief conclusions which we are able to form respecting that rather rare condition auricular flutter, and have stated that flutter as it occurs in man is due to a single wave circulating continuously. In this lecture I propose to deal with the much commoner and therefore more important disorder, auricular fibrilfation. Now these two conditions are very closely related, as has been recog nized for some years; they are known to be related- not only because of several resemblances, but because the one not infrequently passes;into the other. Thus flutter of the auricle, as I pointed out some years ago, may usually be converted into fibrillation by the administration of heavy doses of digitalis ; a conversion which is made use of in the present day therapy of flutter. We shall see presently how the two states are related, and that circus movement underlies both. To explain the interrelation it is necessary for me to expand what I have already touched upon-namely, certain reactions of the auricular muscle to increased rate of beating. We must study in more detail the change which occurs in the length of the refractory period and in the rate at which the waves trave as the rate of beating rises.

\section{Influence of Heart Rate on the Refractory} Phase, etc.

The changes are somewhat complex, and may be illustrated most clearly by means of the accompanying diagram (Fig. I). To the left of the diagram is a doubleheaded arrow, which represents the length of the auricular cycle when the heart is beating at a normal rate. This cycle is divisible into two parts, as indicated by the two double headed arrows which stand just to the right of the first; it is divisible into the refractory period, during which the auricular muscle is in the excited or contracted state, and into the responsive period, during which the muscle is inactive or resting. I represent the refractory period in black and the responsive period in white, and the remainder of the diagram shows, on the basis of direct obsirvation, how these two periods are proportioned to each other as the heart rate is raised. As the heart rate rises by equal increments-say from 100 to 150 to 200 to 250, etc., - so the length of the cycle shortens. If the lengths of the cycles, as these shorten, are charted vertically upon a horizontal base line (as in the figure), their ends join up to form a curve, the steepness of which gradually decreases: The curve of the end of the cycle approaches the base line, at first rapidly, but gradually less rapidly. The two lines will meet at infinity. The end of the refractory period also forms a curve which moves towards the base line (it is represented by the top edge of the black portion of the figure). Briefly, the refractory period of the muscle shortens as does the length of the contraction when the heart rate is raised. But the refractory period does not shorten to the same extent as does the length of the cycle; consequently the responsive period dwindles when the rate is advanced. It dwindles until, eventually and at a very high rate of beating, it disappears altogether. When this happens the muscle will not respond to every impulse reaching it; it breaks into what has been termed $2: 1$ (or half) response-that is to say, it reaponds only to aiternate impulses entering it. That is but natural, seeing that only alternate impulses will fall during the responsive period of preceding cycles.

Now the precise manner in which this alternating response is foreshadowed in the mammalian auricle is

* Delivered before the Royal College of Physicians of London, 
peculiar, and considerably important; it is necessary thoroughly to understand it. As the rate of beating rises, and the period of responsiveness shortens, a time comes when the muscle develops what is spoken of as a partially refractory period. It is a phase of the cycle, during which the muscle as a whole may or may not respond to stimulation. When this partially refractory phase first develops the cycle seems to be divisible into three parts: at the beginning is the absolutely re. fractory phase; this is succeeded by a partially refractory phase; a short phase remains at the very end of the cycle, during which the muscle is always responsive to stimu. lation. But the end of the partially refractory phase is not sharply defined; it fades imperceptibly into the phase of responsiveness, If you will, the matter may be expressed somewhat differ. ently. During the early and greater part of the cycle the muscle is quite re. fractory, but the end of this phase is no longer clean cut and determinate; if at one instant the muscle is wholly refractory, at the next instant it is not

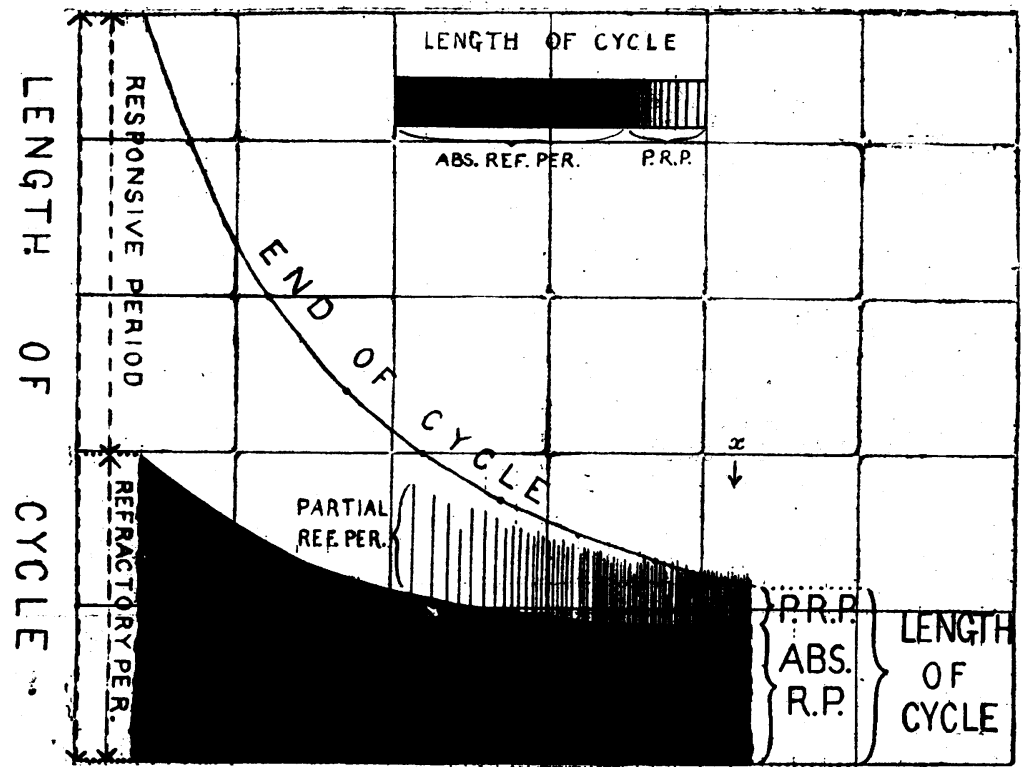

Fig. I.-The main diagram illustrates the relation of the refractory period to the length of the cycles when the auricular rate is raised by equal increments from its normal rate to a high level. The black portion of the diagram represents the absolute refractory period, which shortens as the rate is raised (that is, reading from left to right): a curved line indicates the shortening of the cycle itself. P.R.P.= period of partial refractoriness. $A B S . R . P .=$ period of absolute refractoriness.
I have dealt with this question of partial refractoriness at some length because it is essential that it be compre hended fully and clearly. It is a phenomenon which has fundamental influences upon the action of the auricle beating at very advanced rates. What I especially desire to empliasize is that, at these advanced rates of beating, each excitation wave entering the muscle finds that muscle imperfectly recovered from the passage of its predecessor.

Let us apply the small diagram in the to our picture of a circulating wave. In the diagrams of the ring experiment shown in the last lecture I represented the circulating wave in its most simple form. The relations there shown be tween the advanc ing crest of the wave and its wake of re treat represent what is occasionally found in actual experiment. More usually, however, the relation in flutter is a little more complex. The gap between the crest and wake does not consist of wholly responsive but of partially refractory muscle (see Fig. II) The on-moving crest fibres which are re sponsive; it finds upper part of Fig. I encounters many wholly responsive; the refractoriness fades away gradually (through the partially refractory period) and responsiveness gradually develops. The state of refractoriness is found to be denser as it is traced backwards through the cycle until at last it becomes absolute. The development of the partially refractory phase, which is a phenomenon of high rates of beating, expedites the closure of the gap between the end of the absolute refractory period and the end of the cycle. The precise instant at which the state of partial refractoriness ends is not measurable, but it is certain that, as the rate of beating advances, it soon bridges the gap completely. Whien this stage is reached the cycle is divisible into two namely, a plase of absolute refractoriness and a phase of partial refractoriness; there is no true or wholly responsive phase. This state of the muscle is represented in a small diagram above the main figure.

The meaning of the change which I have de. scribed is not obscure; it is this: when the rate is sufficiently raised, the muscle fibres do not all contract during each cycle,

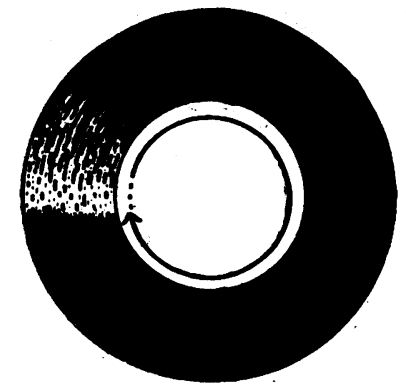

II. some which are still refractory. sefiactory fibres from side to side, passing only where it finds channels open and ready to receive it. It is as though a second prairie fire followed a first, but followed it at a time when the vegetation formerly burnt had not fully returned to its old condition; there would be places where the cinders of the first fire still blackened the earth, and the second flame in passing would creep around the

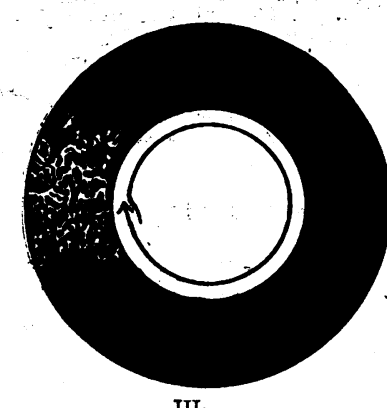

III.
FIG. II.-A schematic representation of the excitation wave as it circulates in flutter. The blackened portions of the ring represen those portions of the muscle which are refractory at a given instant. The crest of the wave travels constantly through muscle in a partially refractory stato. The border of the advancing wave is finely serrated.

FIG. III.-A similar representation of the excitation wave as it circulates in fibrillation. The advancing border and retreatin wake are deeply crenated, and these crenations overlap. The wave is constantly advancing through small and irregular channels of responsive tissue as these open up to receive it. odge of these before it could go forward. These barriers, by deflecting it, render the onrushing wave sinuous in its course, and delay its progress from point to point.

I said in my first lecture which the wave is trans. mitted is not usually normal, but that it is slower than normal. We have proof that this delay is not due to change in the rate of fibre conduction, but to small barriers of unrecovered (or refractory) fibres. This observation is one of nolittle consequence, since it much simplifies our conception of those factors which are respon. sible for the maintenance that in flutter the rate at some contract in alternate cycles only, and the critical rate at which regular response fails is not the same for all the muscle fibres; some fail to respond earlier than do others. During the phase of absolute refractoriness all the flibres are, refractory to stimulation, during the remainder of the cycle the fibres one after another recover their excitability, the muscle as a whole becomes more and more responsive therefore, but up to the very end of the cycle some fibres still remain refractory. of circulating waves. These factors are three-namely, the length of the muscle path, the rate of propagation from point to point, and the duration of the effective pefractory period. We now see that the second factor is controlled by the third. In large measure the length of the path is also controlled by the refractory the path along which it most closely follows its own wake. phase; for, where several channels are open to the crest of the circulating wave it will take the shortest, and that is 
In studies of flutter, and in those of fibrillation, refractory pericd becomes of prime importance. Its length, and especially the length and character of its partial phase, dre responsible not only for the maintenance of circulating waves, but, as we shall see, for the particular form of disordered novement which the auricle assimes.

The Production of Experinental Fibrillatión.

It has been'stated previously that a frequent first step towards linowledge comes when we produce, by experinienting upon animals, a con ition identical with that seen in our patients. In so far as fibrillation of' the "auricle is concerned that step wás taken eleven years ago. At that time a condition termed fibriflation of tlie auricles tras ivell known to $\mathrm{Cx}$ peininenters, a r a a "common form of disordered he'a r t action was recog nized in patients: but neither the experimental nor the elinical condition had been examined sufficiently closely to make it clear that the two states are one and the same. This identity was proved "when thic electrocardio. grams of the experimental ard
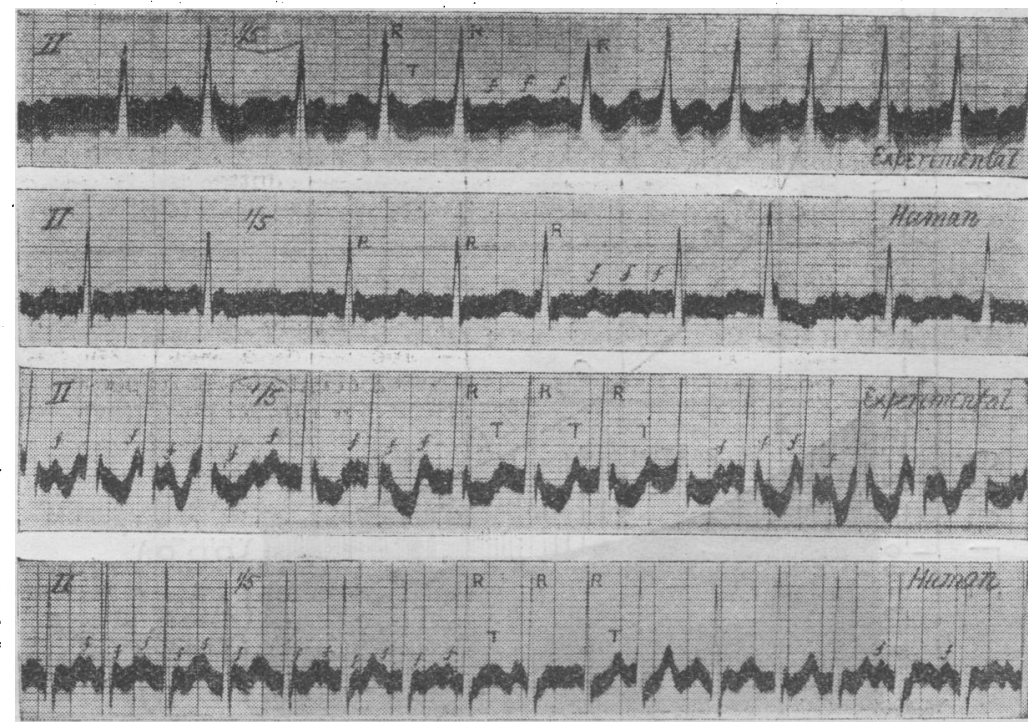

Fia. IV.-Four electrocartiograms (lead II) illustrating fibrillation of the auricles in man and the dos. The first and third curves are from doss, and have been talien from recent experiments in which fibrillation of the auricles has been aualysed. These two curves should be compared with the second and fourth respectivcly; these last are cxamples of clinical fibrillation.. R.and ' $t$ ' are venuricular detlectious; if are the oscillations arising from the fibrillating auricles. pelinical conditions were submitted to close comparison by Rotlıberger and Winterber's and myself in 1909, and when a little later I sought and obtaired the opportunity of exposing to view the heart of a horse suffering from the same malady as do our patients.

Since the time of these demonstrations the term fibrilla. tion of tre aúnicle has come to be used universally in describing this particular disorder of the hinian heart.' In Fig. IV I show again electrocardiograms of the experimental and clinical conditions. Treated pictorialiy the curves of auricular tibril-

lations are; within certain limits, variable; but exactly comparable variatrons are to - be seen in than and animal. The variability of the picture is in large part governed by the action of the ven. tricles. As you are aware, the rate of the ventricu. lar action is not always the same, neither is the degree of its irregularity in different samples of tibrillation. It is not difficult to choose from a collection of clinical curves on the one hand and experimental curves

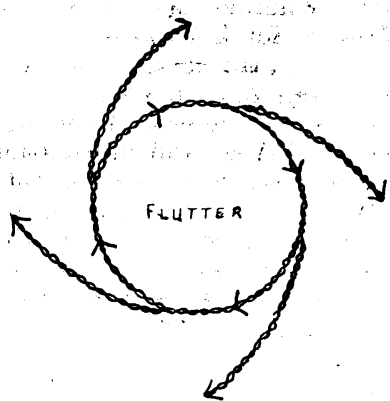

Firi. V.-1 diagram illustrating the successive patbs followed by the excitation wave in flutter. The path is tinely sinnous, but is in general aceurately repeated from cycle to cycle. on the other hand, ex. amples in which the resemblance is so close as to be con vincing. With the details of the curves I need not now detain you, but would remind you of their most constant features. The ventricular representatives $(R$ and $T)$ are frequent and irregularly placed; the auricular representatives comprise a series of oscillations, of irregular foim and somewhat irregular incidence and amplitude. The auricular representatives in flutter are united end to end the action is ruite regular and continuous, and its mean räte is approximately 300 per minute. The auricular representatives in

fibrillation are not very dissimilar to theso; they are also joined end to end; and the action is again continuous. 'The auricular action in flutter and fibrillation differs, however, in important respects; thus, in fibrillation it is 50 per cent. faster, the oscillations having a meair rate of about 450 per minute; another difference is that in fibrillaaccurately repeated; sometimes of curve there may be at least suggestion of repetition (as in the last record of Fig. IV) but close measurement will show that it is not precise; moreover, it is not l ong maintained. Cliange is the rule.

Thie Nature or

Fibrillation and its Relation to Fluterer.

I have pointed out that the first step in this inquiry was taken eleven years ago, when it Iv a s ascertained tliat the clivical. disorder is identical with one which can be produced experimentally but it is to be un dersteod that we then obtained no close insight into fibrillation au fibrillation. Te had obtained knowledge of a disorder of the human heart and, moie important, the means of further investigating it. It is in respect of these further investigations that $I$ shall now speak. The metliod of research has been very similar to that employed in the case of flutter. We produce fibrillation of the auricles in an animal by suitable stimulation, and proceed to examine the patlis taken by the excitation waves through the muscle while this fibrillation continnes. It would be impossible for me to place before you in this lecture the details of this analysis ; I can only attempt to acquaint you with the chief conclusions at which we arrive after fully considering

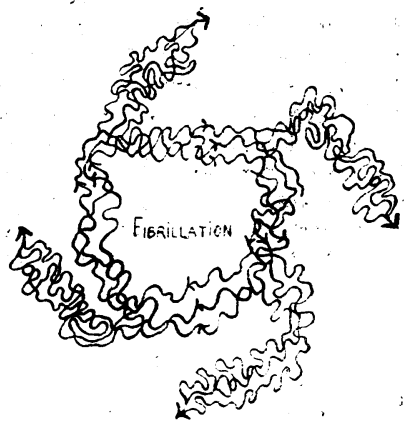

FIG. VI.- t similar diacram of the successive raths talien in ribrillation. The path is coarsely sinuous and ever-tarying, thongh it continues to progress in a clock wise fashion aroud a central area. the evidence derived from all sources. The main conclusion is that fibrilla. tion, Jike flutter, is main. tained by a circulating ivave:- As in flutter, the central circulating wave is a single wave, but the circuit is completed in a shorter time ; the auricu. l ar c y cles, therefore, follow each other more quickly. To what is this quicker movement due ultimately? It is almost certainly due to the path of the circus movement being somewhat shorter than is the case in flutter. Why should the path bo shorter? Probably because in auricles predisposed to fibrillation the effective refractory perior is shorter than in those predisposed to flutier. The crest of the circulating wave in both conditions tends to follow close upon its own wake The refractory muscle forws a ring broken by a small gap: this broken ring, regarded as a whole, revolves. Now the length of refractory tissue in this ring at any given instant is obviously controlled by the duration of the refractory period." A decrease in the refractory period shortens the length of the tissue involved in this 
state at any given noment; consequently, if the gap remains unaltered, the diameter of the ring must shorten. If a snake glides along the path talien by its own tail, the size of the circle which it inscribes will be controlled by the length of the snake.

We believe that in fibrillation the circuit is smaller in diameter than in flutter. We cannot yet describe with confidence the precise paths which are followed; but there is some direct evidence to suggest that the mouth of the superior cava is one of the circuits which the central wave favours. Where precisely the circuit is situated is of little moment. To recognize that a single circuit exists sliould suffice.

The difference between fibrillation and flutter is in part one of rate; but that is not the sole difference or even the most important difference. It has been shown to be the rule that in flutter the crest of the circulating wave is constantly passing through tissue in a partially refractoxy state. The wave as it progresses strikes upon small barriers which render its course finely sinuous. In fibril. lation this interference is much exaggerated; the barriers are larger and the crest travels along paths coarsely sinuous. Seemingly, the crest lias not a straight or simply curved border of advance; it is deeply and irregularly crenated. Its wake is similarly crenated and the crenations of the one and the other overlap and intertwine; this relation is shown diagramatically in Fig. III. The crest of advance moves through muscle apparently in a denser state of partial reftactoriness than is the case in flutter.

Picture the path travelled by the wave after it has circulated several times in flutter (Fig. V). There is the track of the central re-entering wave; the path taken is finely sinuous, but apart from these very minor variations it is constant. As this mother wave circulates in the main channel it throws off centrifugal waves at each revolution, and these proceed into outlying areas of the muscle, such as the appendices and the sleeves of muscle on the cavae; along these outlying channels the path is also finely sinuous, but in general constant. The whole muscle of the auricle is involved in each cycle. With each revolution $t l o$ events are repeated; the waves are signalled with almost perfect regularity in every part of the muscu. lature; at each revolution a wave passes to the region of the $A-T$ node, the responses of the ventricle are, therefore, of an orderly character.

Picture similarly the path which the wave has followed aiter it has circulated several times in fibrillation (Fig. VI). Everywhere the track is coarsely sinuous. There are the central tracks, spread over a wider band of tissue than in flutter,* because the path varies. Speaking very broadly, the same central path is trodden over and over again, but in detail there is no constancy. The wave may, and apparently does, encircle the same central area repeatedly if not continuously, but it staggers along its course ; it is a road of many and serious obstacles. For that reason it does not return to its starting point after constant intervals of time; for that reason and because of change in the actual path pursued, the oscillations in the electro. cardiograms are of irregular incidence and form. The paths through the outlying muscle also vary. Place contacts on any region of the auricular muscle, and the waves are not signalled regularly as in flutter, but irregularly; a few even fail to arrive at their proper destinations. With each irregular revolution, or at least with most, a wave passes to the region of the $A-V$ node.t These waves arrive at the node more frequently than they do in flutter, for the general move. ment is somewhat faster; but because the path travelled is coarsely sinuous and variable they arrive at the nodo irregularly. 'The responses of the ventricle are therefor'e irregular.

The Actual Circuits in Flutter and Fibrillation. A single circulating wave is responsible both for flutter and for fibrillation of the auricle; in both conditions it follows the re-entrant path repeatedly, though in flutter this repetition is far more exact than it is in fibrillation. We

* Though the band of tissue involved in successive circuits is wider he average circle is probably of lesser diameter, as already stated. The thorter diameter is not represented in the accompanying diagrami.

The waves which reach the $A-V$ node are approximately one-tenth less numerous than those which flow along the central path. In the average they number, therefore, about 400 per minute in human fibrillation. possess some definite knowledge of the actual paths followed by the wave in the fluttering auricle of the dog. The wave may encircle the mouth of the superior cava and includes a variable amount of tissue lying between this vessel and the inferior cava; or it may encircle together the mouths of both superior and inferior venae cavae; it is probable, though it is not proven, that circuits are formed in some instances around the auriculo-ventricular orifices.

In man the rates in flutter are from 240 to 350 per minute; in the dog the rates are 345 to 580 per minute. In other words, the rates in the dog are approximately 50 per cent. faster. Difference in the size of the organ in man is sufficient to explain this difference of rate, if we assume the rate of transmission in the human and canine aurictes to be equal. We may arrive at a general, if we cannot arrive at a precise, idea of the ring's circumference in the human subject. Thus, if the rate of a human flutter is 240 per minute, the duration of each cycle is 0.25 of a second; if the rate is 350 per minute, the duration of each cycle is 0.17 of a second. Assume that the transmission rate in flutter is 500 millimetres per second then the length of the path will be 125 millimetres in the one case and 85 millimetres in the other, and the diameters of the corresponding circles will be 4 and 2:7 centimetres respectively. Thus, if our assumed transmission rate is correct, the circular paths in flutter are of diameters somewhat exceeding the diameters of the chief orifices of the auricle. It is these natural orifices to which we look especially in attempting to locate the actual paths of the waves.

In human fibrillation the rate of movement is faster; it lies usually in the neighbourhood of 450 per minute, the cycle having a duration of 0.13 of a second. If we assume the same transmission rate, then the length of the path would be $66 \mathrm{~mm}$., and the diameter of the circle would be a little more than $2 \mathrm{~cm}$. It will be evident that if this estimate is approximately correct, and if we suppose the chief orifices of the auricle to be those encircled by the waves in fibrillation, that in this last condition the encirclement must be a very close one. The factor which remains in doubt is, of course, the rate of transmission.

These remarks, Sir, bring me almost to the end of what I propose to record in the present lectuces. I may have been tempted to speak of possible remedies for the state of affoirs which I have described, but the subject is still unripe for discussion; perhaps I have said enough in indicating what seems to me one of the chief lines which investigation should take; it is an investigation of the refractory period of heart muscle, a search for remedies which will influence the duration of this refractory state, and which, by prolonging it, will help us to close the gap between the crest and wake of the circulating wave; for this gap is essential to the maintenance of the circulating wave, whether the circulating wave is responsible for flutter or for fibrillation.

[Finally, the lecturer proceeded to demonstrate shortly his recent experiments with Dr. Drury and Dr. Iliesch upon the movements of the electrical axis of the auricle in clinical flutter and fibrillation. If suitable plaues are chosen it can be shown, in both these conditions, that the electrical axis changes its direction in a definite and striking manner; it revolves through $360^{\circ}$ as each auricular cycle is completed. As the electrical axis may be taken as an index of the general direction in which the wave is travelling, these observations demonstrate that in flutter and fibrillation the wave travels in a circular fashion through the auricle. Taken in conjunction with the experimental evilence, thcy coustitute proof of simple circus movements in the human auricle affected by these two disorders.]

Note.-Full references to the work on flutter and fibrillation will be found in the original papers published in Heart, vols. vii and viii.

ON the occasion of the 25th annicersary of the discovery of the Roentsen rays a monument will be inausurated at Petrograd to Professor Roentgen and a street will be named after him.

'THE tifth meeting of the German Urological Society will be held at Vienna from Soysember 29th to October 1st, when the following subjects will be discussed: (1) Pathology and treatment of hydronephrosis, (2) surgical anatomy of the bladder and urcters in relation to cxtensivo resections. 